\title{
Duas espécies novas de Centris Fabricius do Peru e notas sobre duas outras de São Paulo, Brasil, esquecidas desde a sua descrição (Hymenoptera, Apoidea, Anthophoridae) ${ }^{1}$
}

\author{
Jesus Santiago Moure ${ }^{2}$
}

\begin{abstract}
Two new species of Centris Fabricius from Peru and notes on other two from São Paulo, Brazil, forgotten since their description (Hymenoptera, Apoidea, Anthophoridae). Centris (Ptilocentris) danunciae sp. nov. (Peru, Huanta) and Centris (Melacentris) bitaeniata sp. nov. (Peru, Iquitos) are described. Some taxonomic notes are also given for Centris (Melacentris) dorsata Lepeletier, 1841 (= Centris ehrhardti Schrottky, 1902, syn. nov. = Centris dorsata var. maculosa Friese, 1924, syn. nov.) and Centris (Melacentris) collaris Lepeletier, 1841 (= Centris pocograndensis Schrottky, 1902, syn. nov.), species forgotten since their description. KEY WORDS. Hymenoptera, Apoidea, Anthophoridae, Centris, taxonomy
\end{abstract}

Nas descrições a abreviatura dp indica o tamanho do intervalo entre os pontos, quando comparado ao diâmetro dos mesmos, e os valores entre parêntesis são dados em centésimos de milímetro, quando não há indicação clara de outro valor; (E) esterno e (T) tergo.

Os tipos das duas espécies descritas por SCHROTTKY (1902), estão depositados no Museu de Zoologia da Universidade de São Paulo (MZSP), São Paulo, e os das duas espécies novas na Coleção de Entomologia Pe J.S. Moure, Departamento de Zoologia, Universidade Federal do Paraná (DZUP), Curitiba.

\section{Centris (Ptilocentris) danunciae sp. nov.}

Figs 1-2

Centris de tamanho médio.

Holótipo fêmea. Comprimento total aproximado: 19,1 mm.

Cabeça, tórax, pernas e abdome pardo-anegrados, descontando os fêmures e o primeiro tergo mais para o pardo-castanho-escuro e T4-T6 castanho-claros, cobertos com densa pilosidade preta exceto por um grande triângulo branco-piloso na metade posterior do mesoscuto, continuado sobre todo o escutelo e metade interna das axilas for-mando sua base recurva; alguns pêlos brancos na área supraclipeal e em T1; em T2, faixas marginais apenas nas no bordo anterior e nas extremidades laterais, em T3-T4 as faixas mais completas no bordo posterior, curtamente interrompidas no meio, ao pêlos mais compridos e densamente ramificados, em T5 um pouco para o ferrugíneo, formando a faixa prepigidial; pálido-fer-

1) Contribuição número 1388 do Departamento de Zoologia, Universidade Federal do Paraná.

2) Departamento de Zoologia, Universidade Federal do Paraná. Caixa Postal 19020, 81531-980 Curitiba, Paraná, Brasil. Bolsista do CNPq. 
rugínea aos lados da placa pigidial. Nos esternos formando faixas regulares brancas em E1-E3, ligeiramente amarelada e bilobada em E4 e cobrindo todo E5. Asas moderadamente escuras, com alguns reflexos variegados na porção basal, mais transparentes na parte papilada.

A pontuação praticamente coberta pela densa pilosidade, porém bem evidente no labro: bastante grossa e mais adensada apicalmente (alguns pontos até $60 \mu$ ), na base mais esparsa e intercalada irregularmente por pontos menores $(30-40 \mu)$. O clípeo micro-reticulado, quase sem pontos no disco e quase iguais aos pontos grossos do labro, irregularmente esparsos para os lados; pontos mais adensados na área supraclipeal, deixando mais lisa e com alguns micropontos a área próxima aos ocelos; os micropontos mais notáveis junto às órbitas, mais adensados e com pêlos mais finos na porção posterior do vértice; os lados exteriores dos ocelos estreitamente lisos e alargando-se na área pós-ocelar. Tégulas irregularmente micropontilhadas, na frente mais denso-micropilosas. Nos tergos a pilosidade longa, densoplumosa, porém deixando ver os pontos finos de implantação (cerca de 20 $\mu$ ) separados entre si por cerca de 2-3 dp, em T3 um pouco mais grossos $(30-40 \mu)$, porém nos tergos distais separados entre si apenas por cerca de 1 a 1,5 dp.

Cabeça, mais larga que longa (625:525); os olhos grandes (412:192) com a distância interorbital inferior maior que a superior (350:290), a interocelar quase o dobro da ocelorbital e esta pouco mais que o diâmetro do ocelo médio (112:60:d56); a área malar curta (entre 30 e 40); o clípeo mais largo que longo (312: 230); o escapo pouco mais longo que largo (84:52); o flagelômero basal bem mais longo que os três seguintes juntos (172:40:45:46). Mandíbulas quadridentadas, com o terceiro dente muito curto e pouco saliente. Palpos maxilares quinque-articulados (20:64: 50:20:13) este último com um curto pelinho distal (3); as maxilas moderadamente longas (32 mm) e alargadas (até cerca de 100) depois da implantação dos palpos. Placa basitibial dupla: a superior larga e um pouco excêntrica, sobrepassando atrás a inferior. Placa pigidial dupla, ambas em ângulo agudo, na inferior o ápice arredondado, na superior pouco definido.

No macho o tegumento e a pilosidade como na fêmea, porém a de coloração preta um pouco para o cinzento-escuro, principalmente nas genas, nos lobos pronotais, nos mesepisternos e nas pernas; a pilosidade branca um pouco mais desenvolvida: além do grande triângulo dorsal, aparece mais claramente na área supraclipeal e cobrindo quase todo o primeiro tergo, em T2 irregularmente na base e na faixa apical, esta largamente interrompida, em T3 com interrupção mínima; toda branca, levemente amarelada, cobrindo os quatro últimos segmentos por completo, com alguns pêlos pretos na base de T4 (no meio), e mais extensamente pardo-ferrugínea no disco de T5, ficando um pouco amarelenta e passando a escura no disco de T6-T7; nos esternos esbranquiçada.

Labro colorido de amarelo-claro estreitamente marginado de castanho-escuro; uma larga mancha irregularmente semicircular nos dois terços apicais do clípeo, separada por fina faixa escura do bordo apical e pequena reentrância preta no meio do contorno semicircular superior; uma pequena mancha irregularmente triangular no canto inferior das áreas paroculares; nas mandíbulas uma mancha amarelenta no dente apical. 

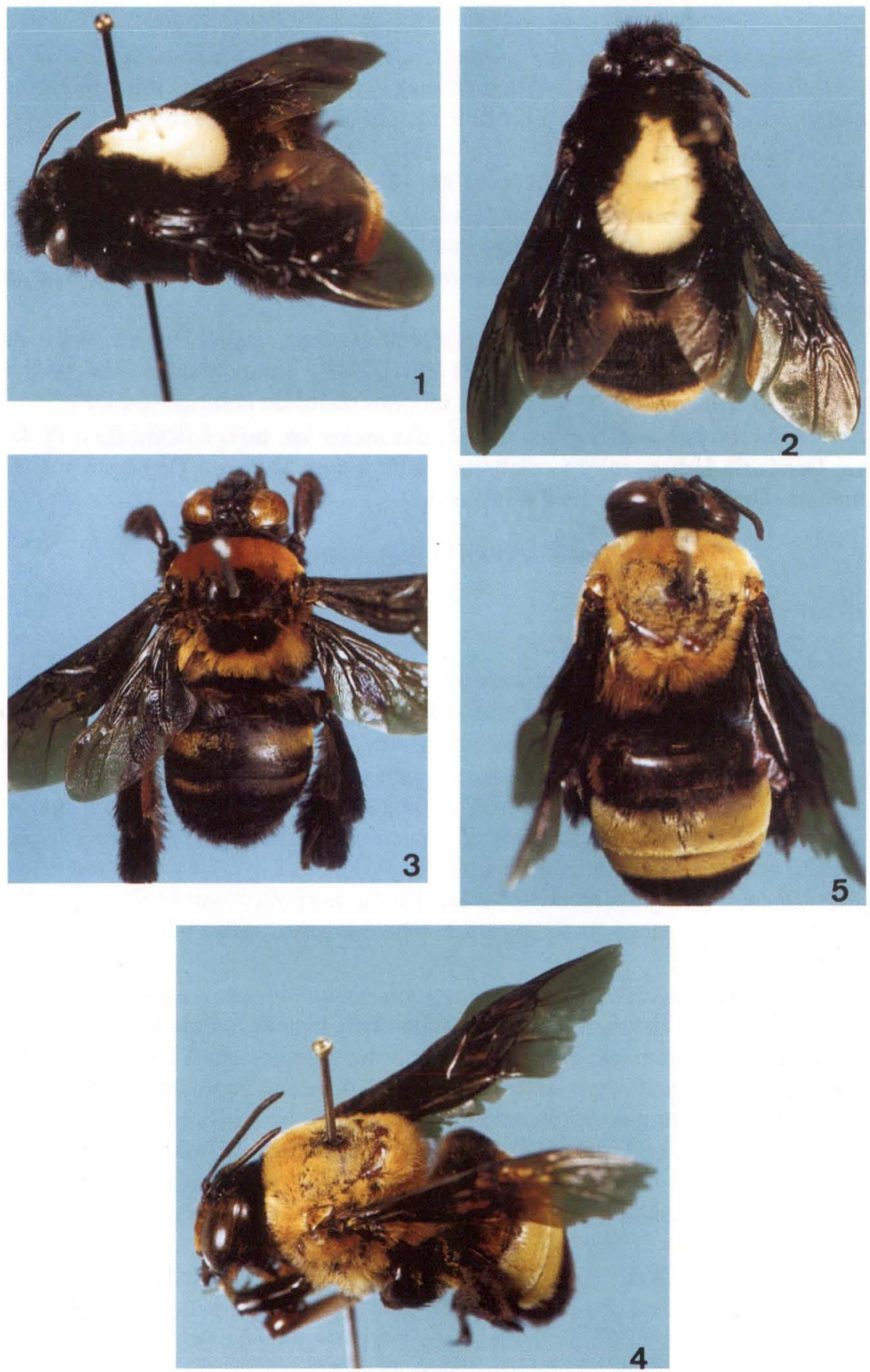

Figs 1-5. (1-2) Centris (Ptilocentris) danunciaesp. nov.; (3) Centris (Melacentris) collaris; (4-5) Centris (Melacentris) bitaeniata sp. nov. 
Pontuação, coberta pela pilosidade como na fêmea. A pilosidade do labro e disco amarelo do clípeo um pouco mais fraca e mais fina. As tégulas brilhantes, com pontinhos muito finos; atrás a pilosidade mais abundante que na frente.

Cabeça, um pouco mais larga que longa (600:465); os olhos grandes (410: 216), mais afastados entre si embaixo (300:160); os ocelos laterais mais próximos às órbitas que meio diâmetro do ocelo médio (70:20:d42). Labro mais longo que o clípeo (145:133). Escapo mais longo que largo (80:50); o flagelômero basal bem mais longo que os três seguintes juntos (140:24:40:40). Palpos labiais com as seguintes medidas (200:560:40:40).

Holótipo fêmea. Peru: Huanta $(2400 \mathrm{~m}$, cerca de $44 \mathrm{~km}$ ao Norte de Ayacucho), 2-IV-1941, F. Woytkowski leg. (DZUP); alótipo macho 7-IV-1941 e um parátipo fêmea 10-IV-1941, com os mesmos dados do holótipo (DZUP).

Etimologia. Centris (Ptilocentris) danunciae sp. nov. é dedicada à Profa. Dra. Danúncia Urban, minha colaboradora de longos anos, no Departamento de Zoologia, Universidade Federal do Paraná.

\section{Centris (Melacentris) bitaeniata sp. nov.}

\section{Figs 4-5}

Centris de tamanho médio.

Holótipo macho. Comprimento total aproximado $(25,00 \mathrm{~mm})$; da asa anterior (21 mm); largura da cabeça $(7,75 \mathrm{~mm})$ e do segundo tergo $(10,45 \mathrm{~mm})$.

Cabeça, tórax, pernas e abdome pardo-anegrados, igualmente todo o abdome descontando o primeiro tergo mais para o pardo-castanho-escuro. O clípeo, labro, paroculares inferiores e terço inferoir da supraclipeal amarelos, com um borrão pardo em forma de parênteses na metade superior do clípeo; uma pequena mancha no dente apical da mandíbula e uma pardo-avermelhado-clara no terço médio do escapo antenal. As tégulas amarelas; as asas pardas, um pouco mais escuras na região venosa basal, a venação pardo-escura e com um certo brilho púrpura-claro nas células distais.

Pilosidade na cabeça preta. O mesotórax, incluindo todo o escutelo, completamente coberto por densa pilosidade amarelo-clara, ficando mais pálida para baixo, e no propódeo fracamente parda, um pouco mais escura em T1 e base de T2; amarelo-clara formando duas faixas largas em T2-T3: em T2 uma faixa preto-pilosa muito estreita ao longo do bordo anterior e em T3 ao longo do bordo posterior, dos outros tergos preta; nas faixas amarelas abdominais os pêlos são mais curtos, densos e com ramificação compacta, se comparado com os dos outros tergos. Nos fêmures anteriores amarelo-pálida, nos médios e posteriores preta, pálida nas tíbias e preta nos tarsos.

Pontuação densa, toda pilígera, coberta pela mesma pilosidade na maior parte do corpo. O clípeo com pontuação fina para o disco; embaixo mais fina e deixando uma longa faixa lisa média um pouco mais larga nos dois quintos superiores, aí o clípeo um pouco deprimido e mais liso, bem como ao longo da estreita carena frontal média inferior. No labro mais densa, principalmente para os lados e para o ápice. $\mathrm{Na}$ fronte, junto aos ocelos, deixando estreitíssima faixa lisa média que se liga à 
carena média, sulcada. No vértice bastante densa deixando pequena área lisa nas ocelorbitais. Escapo muito fino e densamente pontuado. Genas pontuadas, a pontuação ficando muito mais fina e mais densa em direção às órbitas. No mesoscuto relativamente fina para o disco e para trás, mais fraca na parte alta dos tubérculos do escutelo, estes bastante fracos. Nos tergos densa e coberta pela pilosidade. Fêmures bastante lisos, principalmente os anteriores e mais ao longo da parte dorsal.

Cabeça mais larga que longa ( $783 \times 483)$; olhos mais longos que largos, mais afastados entre si inferiormente (325:240); o clípeo bem mais largo embaixo (208:320); as mandíbulas longas (360) e tridentadas além de mais um minúsculo dente basal, o dente apical saliente e agudo; o dente médio com a margem levemente sinuada e o interno com o ápice interno mais agudo; a carena frontal terminando a um diâmetro de ocelo antes do ocelo; distância interalveolar quase o dobro da ocelorbital (72:48:d60); distância ocelorbital claramente menor que o diâmetro do ocelo médio, este colocado bem abaixo do vértice (cerca de dois diâmetros); escapo duas vezes mais longo que largo (120:60), o flagelômero basal claramente mais longo que os três flagelômeros seguintes juntos; as genas, de perfil, mais estreitas que os olhos (145:200). Tubérculos do escutelo bem evidenciados pela depressão entre os mesmos. Placa pigidial moderadamente evidente, pilosa no ápice.

Holótipo macho. PERU: Iquitos, 6-XII-1964, G.H. Dodson leg. (DZUP). Fêmea desconhecida.

Etimologia. O nome da espécie refere-se às duas faixas abdominais.

Comentários. Este exemplar me foi enviado há muitos anos atrás pelo Dr. G.H. Dodson quando estudava o comportamento de Euglossinae na Amazônia Peruana. Foi coletado em Iquitos e, provavelmete, ocorre no Oeste da Amazônia Brasileira.

\section{Centris (Melacentris) dorsata Lepeletier, 1841}

Centris dorsata Lepeletier, 1841: 161. - Burmeister, 1876: 160.

Centris ehrhardti Schrottky, 1902: 579. Syn. nov.

Centris dorsata var. maculosa Friese, 1924: 20. Syn. nov.

Centris proserpina Gribodo, 1891: 11. - Moure, 1960: 8.

SCHROTTKY (1902) definiu a espécie brevemente: "ơ Nigra; nigro-villosa; mesonoto flavo-villoso, clypeo flavo; labro flavo, nigro-piloso; abdomine lateribus haud sericeo-flavo-pilosis; alis cyaneis".

A descrição original de Schrottky refere-se a três machos de Rincão, localidade no Nordeste do Estado de São Paulo, pouco abaixo de Ribeirão Preto, coletados por W. Ehrhardt em fevereiro de 1901. Nessa descrição em latim, haud (= não), está incorretamente usada, pois os exemplares têm pêlos nos lados.

Esses exemplares estão no Museu de Zoologia da Universidade de São Paulo e correspondem à espécie $C$. (Melacentris) dorsata Lepeletier, 1841, cuja descrição está reproduzida abaixo:

"Antennae nigrae. Caput nigrum, nigro villosum. Thorax niger, nigro villosus: dorso luteo-rufo villoso, maculâ nigrâ; scutello nigro, nigro villoso. Abdomen nigrum, violaceo viridique micans; segmentorum secundi tertiique lateribus, quarti 
lateribus et margine infero, quinto toto anoque obsoletè cinereo villosis. Pedes nigri, nigro villosi. Alae violaceo fuscae, aeneo nitentes.

Antennes noires. Tête noire, ses poils noirs. Corselet noir, ses poils noirs; ceux du dos d'un jaune roussâtre, une tache sur ce dos formée par des poils noirs. Ecusson noir, ses poils noirs. Abdomen noir, changeant en violet et en vert; les cotés des deuxième, troisième et quatrième segments ayant quelques poils cendrés, ainsi que le bord inférieur de ce dernier: des poils semblables sur le cinquième et sur l'anus. Pattes noires, leurs poils noirs. Ailes sans transparence, violettes, avec un reflet cuivreux. Femelle.

Patrie inconnue. Musée de France."

O tipo de $C$. (Melacentris) dorsata Lepeletier, 1841, foi visto e estudado em 23-II-1958.

Em outros exemplares dessa espécie, às vezes os tergos dos machos são inteiramente preto-pilosos. Freqüentemente, porém, se observa uma pilosidade cinza-clara, com distribuição irregular em vários espécimens, chegando às vezes a formar faixas mais estreitadas na porção média, em outros apenas em alguns tergos; é freqüente também nos esternos.

Além do tipo no Museu de Paris, foram vistos outros exemplares no American Museum of Natural History, um macho de Jundiaí (São Paulo) e outro exemplar de Aragarças (Goiás). No The Natural History Museum, Londres, uma fêmea, determinado por Smith, 1874, como C. thoracica Lepeletier, 1841; mais uma fêmea sem localidade de coleta; outro exemplar fêmea de Nioaque (Mato Grosso do Sul), coletada por E.D. Jones, 1920. No Museo Civico di Storia Naturale, Geneova, o tipo de Centris proserpina Gribodo, 1891, sem procedência, mas que o autor supõe que seja do Brasil, é mais um sinônimo desta espécie.

No Museu de Berlin encontrei Centris dorsata var. maculosa Friese, 1924; trata-se de um exemplar da Bolívia (Tarata) e que Friese considerou como uma variedade desta espécie, definindo da seguinte forma: " ${ }^{\star}$ " wie $C$. dorsata Lep., aber der mittlere Teil der ausgedehnten Thoraxbehaarung zeigt schwarzbraune Behaarung, der dem sonst typischen dorsata Stück ein ganz fremdartigen Aussehen verleiht".

Os exemplares da Coleção de Entomologia Pe. J.S. Moure (DZUP) são provenientes dos Estados de São Paulo, Minas Gerais, Goiás, Mato Grosso do Sul, Paraná e Santa Catarina. São relativamente comuns onde ocorrem Caesalpiniaceae com rica floração amarela durante o verão (provavelmente Cassia). Nidificam em barrancos.

Tamanho médio: comprimento total aproximado $29,85 \mathrm{~mm}$, asa $20,00 \mathrm{~mm}$; largura média da cabeça $8,00 \mathrm{~mm}$ e de T2 $11,20 \mathrm{~mm}$.

Há variação bastante notável na extensão da pilosidade preta que forma a mancha escura no mesoscuto, mas em nenhum dos espécimens estudados a pilosidade amarela invade o pronoto e os lóbos pronotais, os meso e metepisternos, nem o escutelo. No abdome há uma pilosidade entre branco e cinza, muito reduzida nas fêmeas e mais desenvolvida nos machos, chegando em alguns exemplares a formar fracas faixas marginais mais estreitadas para o meio. Nos machos o labro e grande 
parte do clípeo são de um amarelo-claro, no labro finamente marginado de preto e no clípeo sem chegar aos lados, porém em cima com uma mancha preta (até os 2/5) a cada lado e a parte média atingindo a sutura epistomal ou terminando pouco antes. A pilosidade do labro entretanto, é preta e relativamente densa.

\section{Centris (Melacentris) collaris Lepeletier, 1841}

Fig. 3

Centris collaris Lepeletier, 1841: 162. - Burmeister, 1876: 160.

Centris poçograndensis [sic] Schrottky, 1902: 578. Syn. nov.

SCHROTTKY (1902) definiu a espécie brevemente: " $\sigma^{\star}$ Nigra; cápite nigrovilloso; thorax nigro-villoso, fascia antica usque ad pectus descendente scutellique parte postica ferrugineo-villosis; abdomine nigro, segmentis 2 et 3 fasciis interruptis fulvis; pedibus nigris, nigro-pilosis; alis cyaneis."

Procedente do Estado de São Paulo (Poço Grande). Uma fazenda na antiga Região de Juquiá, de acordo com informações do Dr. Frederico Lane.

Para diferenciar de $C$. collaris Lep., Schrottky invoca principalmente a "côr ferrugínea da pubescência da parte anterior do tórax e da margem posterior do escutelo", no que exatamente coincide com a descrição de Lepeletier, sendo que a diferença real estaria na presença das faixas abdominais, pois Lepeletier diz expressamente: "Abdomen nigrum, nigro villosum."

O tipo de C. (Melacentris) collaris Lepeletier, 1841, foi estudado no Museu de Paris. A descrição original diz: "Antennae nigrae. Caput nigrum, nigro villosum. Thorax niger, nigro villosus; fasciâ anticâ usque ad pectus descendente scutellique parte posticâ rufo villosis. Abdomen nigum, nigro-villosum. Pedes nigri, nigro villosi. Alae violaceo fuscae.

Antennes noires, Tête noire, ses poils noirs. Corselet noir, ses poils noirs; une bande de poils roux, à la partie antéreure, qui descend des deux côtés jusque sur le poitrine; les poils de la parte postérieure de l'écusson également roux. Abdomen noir, ces poils noires. Pattes noires, leurs poils noirs. Ailes sans transparence, violettes. Femelle.

Même localité que les précédentes et même musée. (= Capitainerie de Saint-Paul, au Brésil. Musée de France)".

Considero como diagnóstica a detalhada definição da pilosidade do tórax dada por Lepeletier. No tipo realmente não há faixas abdominais, mas estas foram registradas por BURMEISTER (1876), para exemplares de Lagoa Santa, Minas Gerais: "auch das erste Abdominalsegment hat einen solchen Rand und das zweite jederseits einen gelben Haarbusch". Há na coleção do DZUP, exemplares com faixas e sem faixas nos tergos, como um macho do Paraguai com faixa larga no T2 e uma mais estreita em T3 e imperceptível na base de T4. Uma fêmea e dois machos de Campinas, São Paulo, não são tão característicos para a espécie, mas de inteiro acordo com tipo por ter todo o abdômen preto, preto-piloso: "Abdomen nigrum, nigro villosum." 
AGRADECIMENTOS. Ao Prof. Dr. Albino Morimassa Sakakibara, pelas fotografias dos espécimes aqui estudados. À doutoranda, Favízia Freitas de Oliveira, pela revisão do texto.

\section{REFERÊNCIAS BIBLIOGRÁFICAS}

Burmeister, H. 1876. Hymenopterologische Mitteilungen. Stett. Ent. Ztg. 37: 151-183.

FRIESE, H. 1924. Neue Formen der Bienengattungen Centris-Epicharis. Konowia 3: 19-22.

Gribodo, G. 1891. Contribuzioni imenotterologiche: Sopra alcune specie nuove o poco conosciute di imenotteri antofili. Bull. Soc. Ent. Italiana 23: 102-119.

Lepeletier de Saint-Fargeau, M. 1841. Histoire Naturelle des Insectes. Hyménoptères 2: 1-680.

Moure, J. S. 1960. Abelhas da região neotropical descritas por G. Gribodo (Hymenoptera-Apoidea).

Bol. Univ. Paraná, Zool., Curitiba, 1: 1-18.

Schrotткy, C. 1902. Ensaio sobre as Abelhas Solitárias do Brazil. Revta Mus. Paulista 5: 330-613.

Recebido em 19.VIII.2002; aceito em 25.XI.2002. 